\title{
DOES ANGER EXPRESSION HELP OR HARM LEADER EFFECTIVENESS? THE ROLE OF COMPETENCE-BASED VERSUS INTEGRITY-BASED VIOLATIONS AND ABUSIVE SUPERVISION
}

\author{
LU WANG \\ The Australian National University \\ SIMON RESTUBOG \\ The Australian National University \\ BO SHAO \\ RMIT University \\ VINH LU \\ The Australian National University \\ GERBEN A. VAN KLEEF
University of Amsterdam
}

\begin{abstract}
The question of how leaders' expressions of anger influence their effectiveness has long intrigued researchers and practitioners. Drawing on emotions as social information theory, we suggest the effects of leaders' expressions of anger depend on both the type of violation about which anger is expressed and the type of leader who expresses it. We test this in a series of studies using experimental and field methods. Study 1 shows that a leader's anger expression in response to followers' integrity-based violations enhances observers' perceptions of leader effectiveness, whereas anger in response to followers' competence-based violations diminishes observers' perceptions of leader effectiveness. Study 2 shows that these divergent effects occur because anger in response to integrity-based violations elicits beneficial inferential reactions among followers who observed the anger, whereas anger in response to competence-based violations provokes harmful affective reactions. Study 3 demonstrates that the negative effects of anger expressed toward competence-based violations are exacerbated, and positive effects of anger expressed toward integrity-based violations weakened, when a leader is perceived as abusive. These findings help reconcile divergent perspectives on the effects of leader anger expression, suggesting that anger can enhance perceived leader effectiveness when expressed in the right situation and by the right person.
\end{abstract}

A colleague failing to meet [Amazon CEO] Bezos's exacting standards will set off a nutter. If an employee does not have the right answers or tries to bluff, or takes credit for someone else's work, or exhibits a whiff of internal politics, uncertainty, or frailty in the heat of battle-a blood vessel in Bezos's forehead bulges and his filter falls away. He's capable of hyperbole and harshness in these moments and over the years has delivered some devastating rebukes.

Edwards (2013)

We thank the editor and three anonymous reviewers for their helpful suggestions.
Getting angry ... is easy and everyone can do it; but doing it ... in the right amount, at the right time, for the right end, and in the right way is no longer easy, nor can everyone do it.

Aristotle, Nicomachean Ethics

Effective leadership-defined as a leader's perceived ability to perform the leadership role (Tsui, 1984)_is crucial to organizational performance, yet the path to success is paved with numerous challenges and obstacles (Van Knippenberg \& Hogg, 2003). As the first quote above illustrates, leaders frequently encounter situations in which followers violate their expectations (Fitness, 2000; Geddes \& Callister, 2007; Weiss \& Cropanzano, 1996). Although it is natural for leaders to experience anger 
when their goals and expectations are violated (Averill, 1983; Frijda, 1986), it remains unclear whether expressing anger in such situations helps or hurts leaders' effectiveness. Contributing to the expanding literature on emotions and leadership (e.g., Bono \& Ilies, 2006; George, 2000; Lewis, 2000; Sy, Côté, \& Saavedra, 2005; Van Kleef, Homan, Beersma, Van Knippenberg, Van Knippenberg, \& Damen, 2009; Visser, Van Knippenberg, Van Kleef, \& Wisse, 2013), we investigate whether anger expressions have a differential impact on observers' perceptions of leader effectiveness depending on both the type of violation about which anger is expressed and the type of leader who expresses it.

Despite the consensus that anger expression "matters" in shaping leader effectiveness (Gooty, Connelly, Griffith, \& Gupta, 2010; Rajah, Song, \& Arvey, 2011), there is little agreement on whether it helps or hurts effective leadership (Van Knippenberg \& Van Kleef, 2016). The traditional view highlights the destructive side of anger expressions, noting that they are frequently associated with negative leadership outcomes such as follower dissatisfaction, reduced liking of a leader, and perceived leader ineffectiveness (Glomb \& Hulin, 1997; Lewis, 2000; Madera \& Smith, 2009; Van Knippenberg \& Van Kleef, 2016). For example, reacting to problems with anger can make leaders less effective because anger can contribute to the perception that a leader is abrasive and aggressive and will bully and mistreat employees when something goes wrong (Tepper, 2000). Accordingly, anger is often considered to be a toxic and destructive emotion, implying that effective leaders are those who can keep a cool head and not lose their temper at work even when dealing with serious offenses (Cowan, 2003).

In contrast, other research has challenged this position (Lindebaum \& Fielden, 2011; Tiedens, 2001; Van Kleef et al., 2009; Van Kleef, Homan, Beersma, \& Van Knippenberg, 2010). Highlighting anecdotal evidence that anger is an important part of the management approach of many successful leaders, such as Steve Jobs and Jeff Bezos (Pfeffer, 2010; Sweeney, 2013), some theorists propose that anger expression is not only necessary but also an indispensable tool for leaders in solving problems and eliminating undesirable behaviors in the workplace (Pfeffer, 2010). In support of this view, experimental research has indicated that anger expressions can enhance the expresser's perceived status (Tiedens, 2001) and ability to influence others (for a review, see Van Kleef, Homan, \& Cheshin, 2012).

These divergent perspectives and empirical findings present a puzzle that is as yet unresolved: Does reacting to problems with anger facilitate or hinder effective leadership? Drawing on emotions as social information (EASI) theory (Van Kleef, 2009, 2016), which suggests that emotional expressions exert interpersonal influence via both an affective pathway and an inferential pathway, we propose that the effects of anger expression depend on both the type of violation that elicits the anger and the type of leader who expresses it. Although violation of leaders' expectations represents one of the key factors causing leaders to express anger (Fitness, 2000; Weiss \& Cropanzano, 1996), previous research has not considered whether expressing anger about different types of violations produces differential outcomes. Invoking the dual-path logic of the EASI model, we suggest that competence-based and integrity-based violations activate distinct pathways of influence and therefore cause anger to have divergent effects on observers' perceptions of leader effectiveness. In addition, integrating EASI theory with abusive supervision research (Tepper, 2000), we further expand the theoretical reach of this paper by identifying a critical boundary condition: anger that is expressed by leaders who are perceived to be abusive harms observers' evaluations of leader effectiveness, regardless of the type of violation eliciting the anger.

The present research contributes to our understanding of observers' reactions to leader anger expression in three important ways. First, it shows that the effects of leaders' anger expressions depend on whether the type of violation is competence- or integrity-based (Study 1). Second, it explains why these differential effects occur by invoking both observers' affective and inferential responses to leaders' anger expressions (Study 2). Third, it identifies an important boundary condition of the above effects by considering the type of leader who expresses anger (Study 3). We conducted a series of three studies to test these ideas using both experimental and field methods and focusing on observers' reactions to leader anger.

\section{THEORETICAL BACKGROUND AND THEORY DEVELOPMENT}

\section{The Interpersonal Effects of Anger Expressions}

Like any other emotion, anger is not just a private feeling; it also involves changes in an individual's expressive channels (Gardiner, Clark-Metcalf, \& Beebe-Center, 1980; Scherer \& Wallbott, 1994). For example, an angry person often has a distinct and unmistakable expression, such as lowered eye brows, flared nostrils, a red face, a clenched fist, and a loud voice (Ekman, 1984). While the feeling of anger 
influences individuals' own judgments and decisionmaking (Lerner \& Keltner, 2000; Lerner \& Tiedens, 2006), expressions of anger also have important interpersonal consequences (Van Kleef, 2016). Emerging from this interpersonal approach, the current literature suggests that leaders' expressions of anger are a doubleedged sword (Van Knippenberg \& Van Kleef, 2016). On the one hand, anger expressions can undermine effective leadership by eliciting destructive responses from followers (Glomb \& Hulin, 1997; Lewis, 2000). For example, employees are less satisfied at work and less receptive to the influence of their supervisors when the supervisors express anger (Glomb \& Hulin, 1997). Followers may even perceive an angry leader as someone who is likely to mistreat and bully others. These negative reactions can have a detrimental impact on followers, including increased psychological distress, counterproductive work behavior, problem drinking, and turnover (Tepper, 2007). On the other hand, anger expression can enhance effective leadership by inviting constructive responses from followers. A leader's expression of negative affect, and anger in particular, has the potential to enhance leader effectiveness by drawing followers' attention to the anger-provoking situation and communicating to followers critical issues that need to be addressed (Sy et al., 2005; Van Kleef et al., 2009). When a leader suppresses anger, followers may remain unaware of the seriousness of an issue, fail to respond to the issue with appropriate behavioral change, and allow a problem to continue and even get worse.

\section{Competence-based Versus Integrity-based Violations}

We propose that these divergent perspectives on the consequences of leaders' anger expressions may be reconciled by considering the type of problem that triggered the anger in the first place. As illustrated by the opening quote about Jeff Bezos, a number of behaviors (e.g., when an employee does not have the right answer to a question, takes credit for someone else's work, or treats others with disrespect) can violate leaders' expectations and cause leaders to become angry. Although various frameworks have been used to differentiate negative follower behaviors (e.g., Morgeson, Mitchell, \& Liu, 2015), we suggest that many of these can be meaningfully classified into two overarching categories: (1) competence-based violations, which occur when followers fail to apply the technical skills necessary to perform their jobs; and (2) integrity-based violations, which occur when followers breach the ethical and moral standards of the workplace (Kim, Ferrin, Cooper, \& Dirks, 2004).
This categorization is supported by two key considerations. First, the distinction between competenceand integrity-based violations aligns well with research on leader expectations, which also emphasizes two distinct expectations: leaders expect followers to demonstrate both technical competence and ethical integrity when doing their job (Brown \& Treviño, 2006a; Sy, 2010). Therefore, problematic behaviors that violate either expectation can trigger leader anger. Indeed, empirical evidence shows that competence- and integrity-related violations represent the two most common precipitants of manager anger in organizations (Fitness, 2000). Second, research in a number of areas has demonstrated that people respond differently to issues associated with competence versus integrity (Fiske, Cuddy, \& Glick, 2007; Kim et al., 2004; Pancer, Brown, \& Barr, 1999). Within the trust literature, researchers have distinguished between competence-based trust violations and integrity-based trust violations because this distinction has implications for how trust can be restored (Kim et al., 2004). In the impression formation and social cognition literature (Fiske et al., 2007), research also differentiates between behavior pertaining to competence and integrity in the types of impressions they influence. Collectively, these findings support the possibility that anger in response to the two types of violation can produce differential outcomes.

\section{Types of Violations and Interpersonal Effects of Anger Expression}

Followers generally expect their leaders to act developmentally and supportively when followers lack the skills or knowledge to perform their jobs (Brethower, 1993). Therefore, effective leaders are those who are interested in helping and developing followers when they do not have the right skills in place (Scott \& Meyer, 1991). A punitive or disciplinary response is less suitable in this context because people do not believe those who lack job-related knowledge and skills deserve to be punished (Baron, 1990; Heldmann, 1988). In contrast, research on ethical leadership has indicated that, in case of ethical transgressions, leaders are expected to be tough and strict (Hogan \& Emler, 1981; Treviño, 1992; Treviño \& Ball, 1992). When ethical norms are breached, particularly when this involves harm to others, followers believe that their leaders should punish the transgressor severely (Treviño, 1992). This is because punishment of unethical acts represents a form of retributive justice that shapes people's perceptions of fairness (Carlsmith \& Darley, 2008; Hogan \& Emler, 1981). Punishment for the violation of 
fairness rules thus heightens perceptions of fairness, whereas failure to punish such behaviors may give rise to perceptions of injustice (Darley \& Pittman, 2003). In support of this, Treviño and Ball (1992) found that observers' justice evaluations and emotional responses were most positive when organizations delivered the harshest punishment for unethical behaviors.

These context-dependent leadership expectations may cause observers to respond to leaders' anger in different ways. As noted above, problems arising from a lack of job competence call for supportive and developmental leadership behaviors (Brethower, 1993). In this context, an angry reaction signals to observers that a leader assigns blame and intends to punish or reprimand the follower (Lazarus, 1991). The incongruence between what the leader's anger expression signals and what is expected of the leader in light of the situation should lead observers to perceive the anger as less appropriate (Shields, 2005), increasing the chance that anger will backfire. By contrast, problems caused by a lack of ethics and integrity are typically seen as calling for disciplinary and punitive action (Brown \& Treviño, 2006b; Brown, Treviño, \& Harrison, 2005). Therefore, leaders' anger expressions should be seen as a more appropriate and justified emotional reaction in this situation and therefore are most likely to produce positive outcomes, because observers believe that ethical transgressions should be punished (Van Kleef, Wanders, Stamkou, \& Homan, 2015). These considerations lead to the following hypothesis:

Hypothesis 1. The type of violation moderates the impact of leaders' anger expression such that followers perceive a leader as more effective when the leader expresses anger (rather than no emotion) in response to an integrity-based violation (Hypothesis 1a), whereas they perceive a leader as less effective when the leader expresses anger (rather than no emotion) in response to a competence-based violation (Hypothesis $1 \mathrm{~b}$ ).

\section{STUDY 1 METHODS}

\section{Sample and Design}

We conducted a laboratory experiment to test Hypothesis 1 because an experimental design enables us to demonstrate causality of the proposed relationship and to eliminate the effects of potential third variables. The experiment featured a 2 (leader emotional expression: anger vs. neutral) $\times 2$ (type of violation: competencebased vs. integrity-based) between-subjects design. A total of 125 participants ( 81 females; $M_{\text {age }}=22$ years old, $S D_{\text {age }}=1.69$ ) were recruited from a large Australian university. Participants received course credit for their participation in the experiment. Both the participants and the experimenter running the study were blind to the hypotheses.

\section{Procedure}

Consistent with prior studies on anger expression in leadership (e.g., Madera \& Smith, 2009), Study 1 used a scenario-based vignette to assess participants' responses to a hypothetical leader's anger expression. Participants read a scenario about an interaction between a leader (a supervisor named Peter) and a follower (an employee named John) in an insurance company. The interaction occurred after the leader had learned that the follower had exaggerated the benefits of the company's insurance policies to customers. In all conditions, the leader told the follower that he would not want this to happen again. After reading the vignette, participants responded to a series of questions about the leader and provided their demographic information.

\section{Manipulations}

Manipulation of anger expression. The leader's emotional expression was manipulated by describing the leader's emotional reaction to the incident (Schaubroeck \& Shao, 2012). In the anger expression condition, participants learned that the leader became very angry in the meeting. In the neutral emotional expression condition, participants learned that the leader maintained a neutral emotional expression in the meeting.

Manipulation of type of violation. We manipulated the type of violation by varying whether the violation was related to competence or integrity (Kim et al., 2004). In the competence-based violation condition, participants learned that the employee exaggerated the benefits of insurance policies because of his inadequate knowledge of the policies. In the integrity-based violation condition, participants learned that the employee exaggerated the benefits because he wanted to increase his own sales.

\section{Measures}

Anger expression. To examine the effectiveness of the anger expression manipulation, participants answered two questions on a 5-point Likert scale ( $1=$ "strongly disagree," 5 = "strongly agree") about the emotion expressed by the leader in the scenario ("To what extent did the manager show anger/irritation towards the employee?"; the Spearman-Brown coefficient is .84). 
Type of violation. The adequacy of the manipulation of the type of violation was checked using six questions. Three items constituted the competencebased violation measure (sample item: "John broke the rules because he did not understand the insurance policies well”; $\alpha=.91$ ), and three items constituted the integrity-based violation measure (sample item: "John broke the rules because he wanted to increase his own sales number"; $\alpha=.93$ ).

Perceived leader effectiveness. We adapted measures from Madera and Smith (2009) and Norman, Avolio, and Luthans (2010) to assess participants' evaluations of the leader's effectiveness. Participants imagined working for the leader depicted in the scenario and rated the leader on 5-point Likert scales ( 1 = "strongly disagree," 5 = "strongly agree") capturing the participants' global evaluation of the leader's effectiveness ("I would want this person to continue to be the manager of the department," "This person deserves the position of the manager," "I would approve of this manager as a leader," "I would recommend this manager to a friend or close colleague"; $\alpha=.90$ ).

\section{STUDY 1 RESULTS}

\section{Manipulation Checks}

A 2 (emotional expression: anger vs. neutral) $\times 2$ (type of violation: competence-based vs. integritybased) analysis of variance (ANOVA) on the perceived anger expression showed a significant main effect of the anger manipulation, $F(1,119)=122.07, p<.001$, $\eta^{2}=.51 .^{1}$ As intended, the leader in the anger expression condition was perceived to express significantly more anger than the leader in the neutral emotion condition $(M=3.78$ and $M=2.13, p<.001)$. A similar ANOVA on participants' perceptions of the follower's job incompetence showed a main effect of type of violation, $F(1,121)=94.73, p<.001, \eta^{2}=.44$. As expected, participants in the competence-based violation condition were more likely to perceive the follower to lack adequate skills and knowledge than participants in the integrity-based violation condition $(M=3.67$ and $M=2.02, p<.001)$. In addition, there was a main effect of type of violation on participants' perceptions of the follower's integrity-based violation, $F(1,121)=25.98, p<.001, \eta^{2}=.18$. Participants in the integrity-based violation condition were more likely to perceive the follower to have engaged

\footnotetext{
${ }^{1}$ The drop in degrees of freedom is due to two missing values on the manipulation check.
}

in unethical behavior than participants in the competence-based violation condition $(M=4.57$ and $M=3.81, p<.001)$. There were no other main or interaction effects. Therefore, both manipulations were successful.

\section{Perceived Leader Effectiveness}

We predicted that a leader's anger expression in response to followers' competence-based violations would lower participants' evaluations of the leader's effectiveness compared to a neutral expression, whereas a leader's anger expressions in response to followers' integrity-based violations would enhance participants' evaluations of leader effectiveness compared to a neutral expression. Results from a 2 (emotional expression: anger vs. neutral) $\times 2$ (type of violation: competence-based vs. integrity-based) ANOVA on perceived leader effectiveness revealed that there were no main effects of emotional expression, $F(1,121)=.02, p>.10$, or type of violation, $F(1$, $121)=.86, p>.10$, on perceived leader effectiveness. However, there was a significant interaction effect between the leader's anger expression and the type of violation on participants' leader effectiveness ratings, $F(1,121)=10.07, p=.002, \eta^{2}=.08$, indicating that the effect of anger expression on perceived leader effectiveness was moderated by type of violation. The interaction is depicted in Figure 1. In support of our hypothesis, simple effects analysis showed that the leader's anger expression significantly diminished perceived leader effectiveness in the competencebased violation condition $(M=3.12, S D=.86$ for the anger condition vs. $M=3.62, S D=.77$ for the neutral emotion condition), $t(59)=2.42, p=.02$. Moreover, in line with our prediction, the leader's anger expression significantly enhanced perceived leader effectiveness in the integrity-based violation condition $(M=3.46$, $S D=0.88$ for the anger condition vs. $M=3.00, S D=$ .87 for the neutral emotion condition), $t(62)=-2.08$, $p=.04$. Overall, these findings support Hypothesis 1 .

\section{STUDY 1 DISCUSSION}

Although these initial findings are promising, Study 1 does not illuminate why anger expressed in response to the two types of violations produces distinct consequences. In particular, it remains unclear what psychological processes underlie these differential responses to a leader's competencebased versus integrity-based anger expressions. Identifying these psychological mechanisms would enrich our understanding of the role of emotions in 
FIGURE 1

Perceived Leader Effectiveness as a Function of Leader's Emotional Expression and the Type of Violation that Elicited the Leader's Anger in Study 1

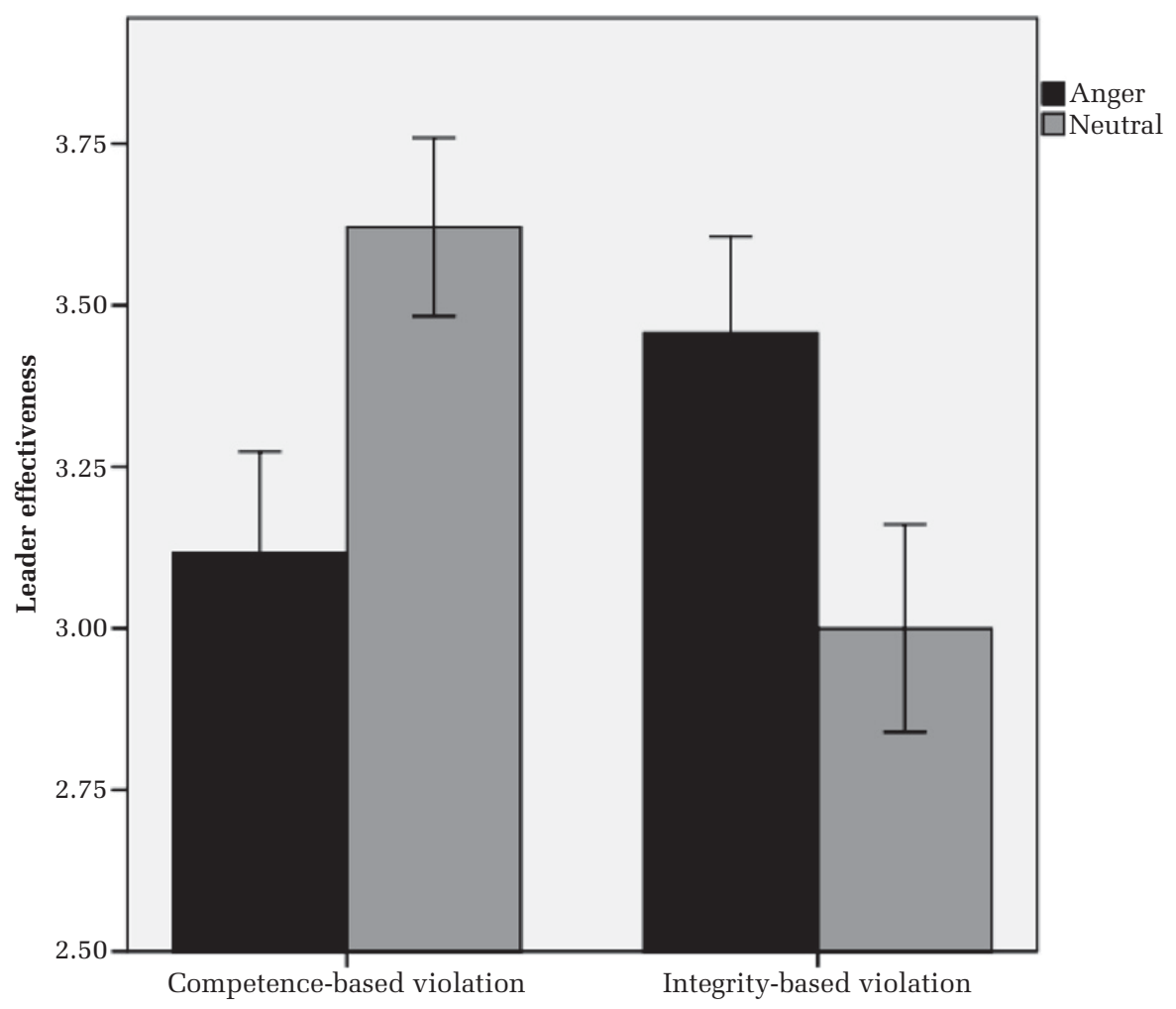

leadership by clarifying why anger expressions play out differently in different situations.

Methodologically, Study 1 used a scenario-based experiment. While this design enabled us to demonstrate causality and rule out alternative explanations (Highhouse, 2009), the fact that we used a "paper person" as a leader may render the anger expression less realistic. Specifically, the use of a scenario may suppress followers' emotional reactions to a leader's anger expression. Therefore, the method used in Study 1 may have overemphasized individuals' cognitive responses and underestimated the influence of emotional reactions to leaders' anger expressions. To address these limitations, we conducted a second study to replicate and extend the findings of Study 1 in an organizational context.

\section{STUDY 2: THE MEDIATING ROLE OF INFERENTIAL AND AFFECTIVE MECHANISMS}

We draw upon EASI theory (Van Kleef, 2009, 2016) to illuminate the psychological mechanisms that explain why leader anger expression has different effects on observers' perceptions of leader effectiveness depending on the type of violation. EASI theory proposes two distinct pathways through which emotional expressions exert interpersonal influence: an affective pathway and an inferential pathway (for a detailed account see Van Kleef, 2016).

Through the affective pathway, emotional expressions elicit affective and visceral reactions in observers (Barsade, 2002; Hatfield, Cacioppo, \& Rapson, 1994), which in turn have downstream consequences for observers' behaviors through various forms of affect infusion (Forgas \& George, 2001). The affective pathway has received strong support in the leadership literature (Barsade, 2002; Bono \& Ilies, 2006; Eberly \& Fong, 2013), with evidence showing that followers are more likely to experience negative and unpleasant emotions after observing leaders who express anger (Glomb \& Hulin, 1997). Furthermore, observers' negative affective reactions can reduce their satisfaction and lower their evaluations of the leader's effectiveness (Bono \& Ilies, 2006; Eberly \& Fong, 2013; Gaddis, Connelly, \& Mumford, 2004; Glomb \& Hulin, 1997; Lewis, 2000). On the basis of 
these findings, responding to problematic behaviors with anger would not help leaders resolve the problems when anger exerts an affective influence on followers who observe the anger. This is because followers' negative affective reactions are likely to hinder leaders' influence attempts and reduce their evaluation of the leader's effectiveness.

Through the inferential pathway, emotional expressions trigger cognitive processes in observers. Because emotions arise in response to events that are relevant to a person's goals (Frijda, 1986; Lazarus, 1991), emotional expressions provide information not just to the person who experiences the emotion but also to those who observe the expressions (Keltner \& Haidt, 1999; Van Kleef, 2009). By thinking about the meaning and implications of others' emotional expressions, observers gain access to the expresser's inner world, enabling them to behave more adaptively in their subsequent interactions with the expresser. The inferential influence of anger expression has also been demonstrated in leadership research, with evidence showing that followers infer from their leader's anger that a particular behavior or a situation is unacceptable. For example, Van Kleef and colleagues (2009) found that team members inferred from their team leader's anger that their efforts on a task were insufficient. It is important to note that inferential responses can also occur when a leader's anger is directed at another person (Van Kleef, 2016). For example, when an individual arrives late at an important meeting, both the individual who is late and those who are on time can make the same inference from a leader's anger that showing up late to important meetings is an unacceptable behavior. Such inferences of unacceptable behavior create a strong motivation for followers who observe the anger to change or avoid such behavior. In the study by Van Kleef and colleagues (2009), followers exerted more effort after inferring from their leaders' anger that their previous efforts were not satisfactory. Thus, when anger exerts an inferential influence on followers, responding to problems with anger can help leaders eliminate a problematic behavior because followers infer from the anger expression that such behavior is unacceptable.

Although both processes may be triggered by a leader's expressions of anger, EASI theory posits that the relative strength of the two processes depends on the perceived appropriateness of the emotional expression (Van Kleef, 2016). Van Kleef and colleagues (2012: 318) have noted that "responses to others' emotional expressions in the workplace are more likely to be driven by negative affective reactions (relative to inferential processes) to the degree that organization members perceive the emotional expressions as inappropriate". This is because inappropriate emotional expressions offer less diagnostic or useful information about the situation and hence observers are less motivated to engage in deep and thorough information processing (Chi \& Ho, 2014; Van Kleef et al., 2009, 2012). A leader's expressions of anger that are perceived as justified and appropriate are thus more likely to elicit inferential processes in followers, whereas expressions of anger that are perceived as unjustified and inappropriate are more likely to elicit negative affective reactions in followers.

Here, we apply EASI theory and propose that anger in response to competence-based violations primarily triggers negative affective reactions in followers who observe the anger, because angry responses to lack of competence are perceived as less appropriate. That is, followers are more likely to experience negative emotions themselves when they observe a leader expressing anger in response to competence-based violations. Conversely, expressions of anger in response to integrity-based violations trigger comparatively less negative affective reactions and stronger inferential processes in observers because people expect angry responses to moral transgressions (Van Kleef et al., 2015) and see such situations as calling for disciplinary and punitive action (Brown \& Treviño, 2006b; Brown et al., 2005). In this case, followers are more likely to infer from the leader's anger that the unethical behavior is unacceptable in their organization. Leader's anger helps eliminate unethical behavior and therefore should enhance observers' perceptions of the leader's effectiveness. Based on these considerations, we propose:

Hypothesis 2. The positive effect of anger expressions in response to integrity-based violations on perceived leader effectiveness is mediated by followers' inferences that the conduct is unacceptable (Hypothesis 2a), whereas the negative effect of anger expressions in response to competence-based violations on perceived leader effectiveness is mediated by followers' negative affective reactions (Hypothesis $2 b$ ).

\section{STUDY 2 METHOD}

\section{Sample and Procedure}

A total of 199 individuals recruited from Mechanical Turk (MTurk) participated in this study for U.S. $\$ 3.50 .^{2}$ Of these, 34 participants $(16 \%)$ were

\footnotetext{
${ }^{2}$ We followed best practices for collecting MTurk data. In particular, we selected "high quality" participants (Landers \& Behrend, 2015) by recruiting only "master workers" residing in the United States who had completed at least 50 tasks and who had higher than $80 \%$ approval ratings.
} 
removed from the analysis because they failed the validation questions built into the study (e.g., "for this item, please select 'strongly agree'”), provided inconsistent data on their demographic information, omitted a substantial portion of data, or gave the same response across all variables. Our final sample size was therefore 165 . The sample was $63.6 \%$ female, and the average age was 39.41 years $(S D=$ 11.43). Participants came from a variety of job roles including accounting and finance, customer service, general management, marketing and sales, human resources and information technology.

In line with previous work using the critical incident technique (e.g., Aquino, Tripp, \& Bies, 2006), participants described an incident of a workplace violation that was committed by an employee in the past six months, and indicated how a leader in their organization had responded to the violation. If no such incident had occurred within this time frame, they were asked to describe the most recent incident. The study had two between-subjects conditions: competence-based violation versus integrity-based violation. In the competence-based violation condition, participants described a violation relating to an employee's lack of work-related skills and knowledge, whereas in the integrity-based violation condition, participants described a violation relating to an employee's lack of ethical principles and integrity.

\section{Measures}

All measures were rated on 7-point Likert scales (1 = "strongly disagree," 7 = "strongly agree").

Anger expression. In both conditions, participants reported their leader's emotional reaction in response to the violation. Three items were averaged to assess the extent to which the leader expressed anger ("The supervisor was irritated by the employee"; "The supervisor showed anger to the employee; "The supervisor was annoyed by the employee"; $\alpha=.87$ ).

Inferential response: Inference of unacceptable conduct. To measure the extent to which participants engaged in inferential responses to the leader's anger, we used the five-item inferential response scale developed by Van Kleef and colleagues (2009) (e.g., "I think the supervisor thought the employee had acted poorly"; $\alpha=.88$ ). ${ }^{3}$ In particular, this scale captures the extent to which participants inferred from the leader's

\footnotetext{
${ }^{3}$ For additional validity information of the inferential response scale, please contact the first author.
}

anger that the behavior that elicited the anger expression was appreciated versus unacceptable.

Affective response: Followers' negative emotions. To assess the extent to which participants themselves experienced negative emotions as a result of observing how their leader handled the violation, participants responded to a three-item scale from Van Kleef and colleagues (2009) about the extent to which their supervisor made them feel angry (e.g., "The supervisor made me angry"; $\alpha=.93$ ).

Perceived leader effectiveness. Participants provided their evaluation of the leader's effectiveness using a three-item scale developed by Tsui (1984) that has been used in previous leadership research (Moorman, Darnold, \& Priesemuth, 2013; e.g., "This supervisor performed his/her job the way I would like it to be performed in the situation"; $\alpha=.94){ }^{4}$

Control variables. Participants' age and gender could be related to their evaluations of leader effectiveness, because age and gender may influence followers' preferences for different leader behaviors (Ayman, 1993; Rodriguez, Green, \& Ree, 2003). Therefore, we included these variables as controls.

\section{STUDY 2 RESULTS}

Descriptive statistics and zero-order correlations are presented in Table 1. Correlations among the substantive variables were all in the predicted directions.

For Hypothesis 1, we tested a conditional direct effect of anger expression on leader effectiveness to examine whether the direct association between anger expression and leader effectiveness is conditional on the type of violation. For Hypothesis 2, we analyzed whether the indirect effect of anger expression via the two pathways was conditional on the type of violation. Edwards and Lambert (2007) recommend generating 95\% bias-corrected bootstrapped confidence intervals (CIs) to assess the

\footnotetext{
${ }^{4}$ In order to further examine the construct validity of this leader effectiveness measure, we collected data from an independent sample of 100 full-time leaders (supervisors). We requested their subordinates to rate their effectiveness as leaders with the measure by Tsui (1984). We also requested the leaders' manager to rate their in-role performance (e.g., this person consistently meets formal performance requirements of his/her job; Williams \& Anderson, 1991). The correlation between managerreported supervisor's in-role performance and the leader effectiveness measure was .77, $p<.001$.
} 
TABLE 1

Descriptive Statistics and Zero-Order Correlations of Variables in Study 2

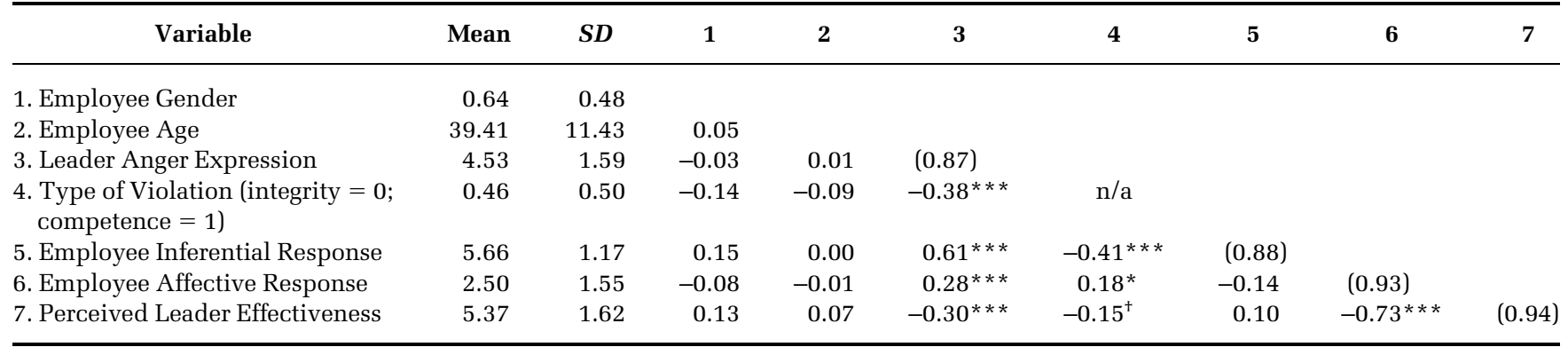

Note: Reliability coefficients are displayed within parentheses in the diagonal.

${ }^{\dagger} p<.10$

${ }^{*} p<.05$

$* * * p<.001$

significance of the conditional indirect effect. In testing these conditional indirect and direct effects, we used Hayes's (2013) "PROCESS" macro (Model 8) for SPSS to estimate the model and to obtain biascorrected bootstrapped confidence intervals (using 5,000 bootstrap samples) for the conditional indirect and direct effects. Tables 2 and 3 summarize these results.

Hypothesis 1 proposed that the relationship between anger expression and leader effectiveness is moderated by type of violation. The interaction term involving anger expression and type of violation was marginally significant $(B=-.22, t=-1.72, p=.086)$. We conducted a simple slope analysis to gain additional insight into the nature of the interaction. This analysis revealed that the association between anger expression and perceived leader effectiveness was negative and significant in the competence-based violation condition $(B=-.33, S E=.11, t=-3.09$, $95 \%$ CI $[-.54,-.12], p<.01)$. However, the relationship between anger expression and leader effectiveness was non-significant in the integrity-based violation condition $(B=-.11, S E=.10, t=-1.08$, $95 \%$ CI $[-.30, .09], p=.28)$. Therefore, Hypothesis 1 only received partial support.

Hypothesis 2 proposed that anger expression in response to integrity-based violations communicate to followers that a particular behavior is unacceptable, which would enhance perceived leader effectiveness (Hypothesis 2a), whereas anger expressions in response to competence-based violations increase followers' negative emotions, which in turn would lower perceived leader effectiveness (Hypothesis $2 \mathrm{~b}$ ). The results pertaining to these hypotheses are presented in Table 3. Consistent with our predictions, results showed a significant conditional indirect

TABLE 2

Regression Analysis Results of Study 2

\begin{tabular}{|c|c|c|c|c|c|c|}
\hline \multirow[b]{2}{*}{ Predictor } & \multicolumn{2}{|c|}{$\begin{array}{c}\text { Employee Inferential } \\
\text { Response }\end{array}$} & \multicolumn{2}{|c|}{$\begin{array}{c}\text { Employee Affective } \\
\text { Response }\end{array}$} & \multicolumn{2}{|c|}{$\begin{array}{l}\text { Perceived Leader } \\
\text { Effectiveness }\end{array}$} \\
\hline & $\boldsymbol{B}$ & $S E$ & $\boldsymbol{B}$ & $S E$ & $\boldsymbol{B}$ & $S E$ \\
\hline Employee Gender & & & & & 0.16 & 0.18 \\
\hline Employee Age & & & & & 0.01 & 0.01 \\
\hline Leader Anger Expression (LAE) & $.24 * * *$ & 0.08 & .16 & 0.12 & -0.11 & 0.10 \\
\hline Employee Inferential Response & & & & & $0.20^{\dagger}$ & 0.11 \\
\hline Employee Affective Response & & & & & $-0.64 * * *$ & 0.07 \\
\hline$R^{2}$ & $.43^{* * *}$ & & $.21 * * *$ & & $0.58^{* * *}$ & 0.0 \\
\hline
\end{tabular}

\footnotetext{
${ }^{+} p<.10$

${ }^{*} p<.05$

$* * * p<.001$
} 
TABLE 3

Summary of Estimates and Bias-Corrected Bootstrapped 95\% Confidence Intervals for Conditional Indirect Effects of Leader Anger Expression on Perceived Leader Effectiveness as a Function of the Type of Violation in Study 2

\begin{tabular}{|c|c|c|c|c|}
\hline \multirow[b]{2}{*}{ Mediator } & \multirow[b]{2}{*}{ Type of Violation } & \multicolumn{3}{|c|}{ Perceived Leader Effectiveness } \\
\hline & & Estimate & Boot $S E$ & $\mathbf{9 5} \% \mathrm{CI}$ \\
\hline \multirow[t]{2}{*}{ Via Affective Response } & Competence-based violation & -0.35 & 0.08 & {$[-0.52,-0.21]$} \\
\hline & Integrity-based violation & -0.10 & 0.06 & {$[-0.23,0.02]$} \\
\hline \multirow[t]{2}{*}{ Via Inferential Response } & Competence-based violation & 0.10 & 0.05 & {$[-0.002, .021]$} \\
\hline & Integrity-based violation & 0.05 & 0.03 & {$[0.002,0.12]$} \\
\hline
\end{tabular}

effect of anger expression on perceived leader effectiveness via inferential responses in the integritybased violation condition (Estimate $=.05$, Boot $S E=.03 ; 95 \%$ CI [.002,.12]), but not in the competencebased violation condition (Estimate $=.10$, Boot $S E=$ $.05 ; 95 \%$ CI $[-.002, .21])$. Thus, only anger expressions in response to integrity-based violations triggered inferential responses.

The results further revealed a significant conditional indirect effect of anger expression on perceived leader effectiveness via affective responses in the competence-based violation condition (Estimate $=-.35$, Boot $S E=.08 ; 95 \%$ CI [-.52, - .21]) but not in the integrity-based violation condition (Estimate $=-.10 ;$ Boot $S E=.06 ; 95 \%$ CI $[-.23, .02])$. Thus, consistent with our theorizing, only anger expression in response to competence-based violations triggered negative affective reactions. Altogether, these indirect effect analyses support Hypothesis 2, that the positive effect of anger expression prompted by integrity-based violations on perceived leader effectiveness is primarily driven by inferential processes (Hypothesis 2a), whereas the negative effect of anger expressions prompted by competence-based violations on perceived leader effectiveness is primarily driven by negative affective reactions (Hypothesis $2 b$ ).

\section{STUDY 2 DISCUSSION}

Extending Study 1, Study 2 provides evidence for why the type of violation influences the effects of leader's anger expressions. Mediation analysis indicated that leader's anger in response to integrity-based violations was more likely to elicit inferential responses in observers, which in turn enhanced observers' evaluations of the leader's effectiveness. That is, followers were more likely to infer from the leader's anger that unethical behavior was unacceptable and not tolerated by the leader. This inference in turn was positively associated with their evaluations of the leader. In contrast, leader's anger in response to competencebased violations was more likely to elicit negative affective responses in observers, which in turn reduced observers' evaluations of the leader's effectiveness. That is, observers were more likely to feel negative emotions when leaders expressed anger in response to competence-based violations. These negative emotional reactions in turn were negatively associated with their evaluations of the leader.

While findings from Study 2 help us understand why the divergent effects found in Study 1 occurred, there are some inconsistencies between the two studies. Notably, the conditional direct effect that was significant in Study 1 was only marginally significant in Study 2, and the significant direct relationship between anger expressed in response to integrity-based violations and perceived leader effectiveness that was observed in Study 1 was not significant in Study 2. These inconsistencies might be due to differences between the samples, the research designs, or the operationalizations of the variables between Studies 1 and 2. Nevertheless, the conclusions emerging from Studies 1 and 2 support the general idea that the effects of leaders' expressions of anger depend on the type of violation that elicited the anger.

In addition to methodological differences between Studies 1 and 2, the differences between the patterns of results of the two studies could be taken as an indication that the effect is subject to boundary conditions that were tapped more in Study 2 than in Study 1 . One potential boundary condition that we believe is particularly interesting from both a theoretical and a practical point of view is the type of leader who expresses anger. That is, the benefits of expressing anger about integrity-based violations may not hold for every type of leader. Theoretically, a joint examination of the types of violations that evoke anger and the types of leaders who express the 
anger can inform a better understanding of the situations in which leaders' expressions of anger are likely to be productive or counterproductive. Identifying leader characteristics as a boundary condition of our effect is important because it helps delineate the scope of our proposed model and allows for more targeted managerial recommendations. In Study 3, we examine abusive supervision as a potential boundary condition that may influence the impact of types of violation on leader's anger effectiveness.

\section{STUDY 3: ABUSIVE SUPERVISION AS A BOUNDARY CONDITION}

Study 3 extends Study 2 in three notable ways. First, the design of Study 2 allowed us to obtain only data on leaders' anger in response to either competence-based or integrity-based violations. Because some leaders may express anger in response to both types of violation, it would be important to control for anger in response to one type of violation when examining the effects of anger in response to the other type of violation. To address this, Study 3 utilized a design where leaders reported their anger expression in response to both types of violation. Second, leader effectiveness was evaluated by followers in Studies 1 and 2. A limitation of this approach is that followers' evaluations of a leader's effectiveness may be influenced by factors that may have little to do with the leader's actual ability to eliminate problematic workplace behaviors, such as followers' liking of the leader (Van Knippenberg \& Van Kleef, 2016). For example, followers may evaluate a leader as more effective because they like leaders who express anger toward individuals who cheat and lie in their organization. This line of reasoning suggests that followers' evaluations of leader effectiveness used in Study 1 and 2 may not fully capture whether expressing anger can enhance a leader's influence on followers. To address this limitation, in Study 3 we utilized a different approach to measuring leader effectiveness that is often used in leadership research: the judgment of a leader's superior (Tsui, 1984).

Third, although a sense of when to express anger can help leaders leverage its potential, how anger influences followers may also depend on the type of leader. This is because the appropriateness of anger expression is not only dependent on the context in which the anger is expressed but also on the individual who expresses the anger (Geddes \& Callister, 2007; Glomb \& Hulin, 1997; Lewis, 2000; Van Kleef,
2016). In Study 3, we extend our theoretical model by considering how abusive supervision influences the effects of anger expression observed in Studies 1 and 2. We focus on abusive supervision because abusive supervisors are known for their anger expression in the workplace (Keashly, 1998). Despite this conceptual connection between anger and abusive supervision, however, it remains unclear whether followers respond differently to anger expressions by abusive and non-abusive supervisors.

Some leaders engage in behaviors that can be characterized as tyrannical, hostile, undermining, or abusive (Tepper, 2000). Abusive supervision refers to "subordinates' perceptions of the extent to which supervisors engage in the sustained display of hostile verbal and nonverbal behaviors, excluding physical contact" (Tepper, 2000: 178). These behaviors include "public criticism, invasion of privacy, taking undue credit, withholding needed information, and the silent treatment" (Keashly, 1998: 87). Followers may perceive their leader as abusive through both direct experience (e.g., a leader uses abusive language directly toward the follower; Kiewitz, Restubog, Shoss, Garcia, \& Tang, 2016) and vicarious experience (e.g., the follower has heard or witnessed a leader using abusive language toward others; Mitchell, Vogel, \& Folger, 2015).

Sustained abusive behaviors violate standards of respectful interpersonal treatment and contribute to perceptions of unfairness (Tepper, 2007 for a review; Vogel et al., 2015). Employees who perceive that a supervisor mistreats employees not only have unfavorable views of the supervisor but also resist the supervisor's influence tactics (Tepper, 2007). Building on this insight, we propose that the influence of anger expression on perceived leader effectiveness depends on whether the leader is perceived to be abusive. Although abusive supervisors (just like non-abusive supervisors) may express anger in response to integrity-based and/or competence-based violations, followers who observe the anger are more likely to interpret anger expressions on the part of abusive supervisors as reflecting their sinister motives and destructive interpersonal style rather than the seriousness of the violations (Geddes \& Callister, 2007). As a result, followers who have observed the anger should become less motivated to engage in inferential processes (e.g., thinking about the meaning and implications of their supervisor's anger) (Van Kleef, 2009, 2016). Rather, followers are likely to feel that this is another case where the supervisor is simply expressing anger to abuse another person. 
Given these conditions, even "appropriate" causes for displaying anger (e.g., remedying an unethical behavior) can be perceived as relatively inappropriate when the anger is expressed by a leader who is perceived to be abusive. Therefore, we expect that perceptions of abusiveness increase the perceived inappropriateness of a leader's anger expression, regardless of the type of violation that elicited the anger. Following the logic of EASI theory, outlined above, this should in turn undermine the relative predictive power of the inferential pathway as the leader's anger is seen as less diagnostic of the situation (Van Kleef, 2016), while increasing the predictive power of negative affective reactions, especially considering that abusive leaders tend to trigger intense negative emotional reactions among followers (Frost, 2003).

We thus propose that the positive effects of expressing anger in response to integrity-based violations on perceived leader effectiveness are mitigated when the leader is perceived as abusive, because expressions of anger on the part of abusive leaders are less likely to trigger inferential processes in observers. At the same time, we propose that the negative effects of anger in response to competencebased violations are even stronger when the leader is perceived as abusive, because abusive supervisors tend to arouse stronger negative affective reactions in followers.

Hypothesis 3a. Abusive supervision moderates the relationship between anger expressions in response to integrity-based violations and perceived leader effectiveness, such that the positive relationship between anger expression and perceived leader effectiveness is weaker to the degree that leaders are perceived as abusive.

Hypothesis 3b. Abusive supervision moderates the relationship between anger expressions in response to competence-based violations and perceived leader effectiveness, such that the negative relationship between anger expression and leader effectiveness is stronger to the degree that leaders are perceived as abusive.

\section{STUDY 3 METHODS}

\section{Sample and Procedure}

A total of 444 full-time employees in leadership roles who were enrolled in various part-time postgraduate business and management programs in three educational institutions in the Philippines agreed to participate in a study of leader-follower relationships. Surveys were prepared in English, which is the language of instruction commonly used in Philippine higher education and in business organizations (Bernardo, 2004). All leaders completed questionnaires containing identity codes to allow their responses to be subsequently matched with those of their respective followers and immediate managers. Participating leaders were informed that they could withdraw from the study at any time.

In the first round of data collection, we approached professors teaching in the business school to request research access to their classes. A questionnaire assessing leaders' anger expressions in response to each type of violation was completed during class time. Surveys were returned directly to the research team. A total of 395 leaders returned the surveys, rendering a response rate of $88.96 \%$. In the second round of data collection, two weeks later, we contacted the 395 leaders again, and each of them received two short survey forms. It was asked that the first survey assessing their abusive supervision be given to an immediate subordinate. A second survey form assessing their leader effectiveness was to be given to their immediate manager. Both survey forms were delivered in sealed envelopes. All participants completed the survey forms and returned them using postage-paid reply envelopes addressed to the research team, after which they received gift vouchers for participating in the study. To ensure the integrity of the data, all participants were instructed to sign across the flap of the envelope containing their ratings. We received 364 surveys from the leaders' immediate managers and 353 surveys from the leaders' subordinates, rendering response rates of $92.15 \%$ and $89.37 \%$, respectively. We disregarded surveys with: (a) wrong or missing identity codes; (b) a large number of missing responses (more than $60 \%$ ); and (c) missing responses for the critical incident questions. Overall, the two rounds of data collection resulted in 222 useable and matched leader, follower, and upper manager triads.

There were 96 male and 124 female leaders (two did not report their gender). Average age and tenure were $36.15(S D=9.51)$ and 6.53 years $(S D=6.31)$, respectively. The leaders had a supervisory relationship with their followers for an average of 3.30 years $(S D=$ 3.62). They worked in a variety of occupations, including accounting and finance $(14.4 \%)$, customer service (14\%), legal (2.7\%), general management $(18.9 \%)$, sales and marketing (18\%), manufacturing and engineering $(8.6 \%)$, information technology $(4.1 \%)$, public relations $(1.8 \%)$, government $(7.7 \%)$, and others (9.8\%). Among the followers, 57.7\% were males (one follower's gender was unreported). Average 
age and tenure were 29.07 years $(S D=8.39)$ and 4.03 years $(S D=4.55)$, respectively. Of the leaders' managers, 108 were females (three managers did not report their gender). Their average age and tenure were 44.16 years $(S D=8.52)$ and 9.58 years $(S D=8.20)$, respectively.

\section{Measures}

Anger expression in response to competenceand integrity-based violations. In Study 3, leaders (as opposed to followers) reported their own emotional reactions in response to both types of violation. We asked the leaders to think of two incidents: the first incident involving a subordinate who lacked adequate skills, ability, or knowledge to perform his/her job and the second incident involving a subordinate who lacked integrity or ethics on the job. Immediately following each incident, leaders reported the extent to which they had expressed anger, using the same three items from Study $2(\alpha=.92$ for anger in response to competence-based violations; $\alpha=.93$ for anger in response to integrity-based violations).

Abusive supervision. Abusive supervision was assessed using the 15-item scale developed by Tepper (2000). A subordinate of the focal leader was asked to rate the extent to which the leader had engaged in an array of hostile behaviors (e.g., "My immediate supervisor puts me down in front of others"; $\alpha=.97$ ).

Perceived leader effectiveness. The immediate managers of the focal leaders were instructed to provide an assessment of the leaders' effectiveness using an adapted version of the three-item scale developed by Tsui (1984) ("Overall, to what extent do you feel this person is performing his/her job the way you would like it to be performed?"; "To what extent does this person meet your own expectations in performing his/her managerial roles and responsibilities?"; "If you had your way, to what extent would you change the manner in which s/he is doing the job?"). Following previous practice (Golden, Veiga, \& Simsek, 2006; Skarlicki, Folger, \& Tesluk, 1999), one item was omitted ("If you had your way, to what extent would you change the manner in which s/he is doing the job") to improve the reliability coefficient of the scale. In this sample, the two-item scale exhibited a Spearman-Brown coefficient of .89 .

Control variables. A leader's gender may influence the effectiveness of the leader's anger expressions because of gender-related emotional norms (Lewis, 2000). Furthermore, leader age and tenure have been found to influence leader effectiveness (Fisher, 1986; Kim, Min, \& Cha, 1999; Zacher, Rosing, Henning, \& Frese, 2011). Therefore, we included these variables as controls.

\section{STUDY 3 RESULTS}

Descriptive statistics and zero-order correlations are presented in Table 4 . All correlations were in the predicted directions. Before analyzing the data, we conducted a confirmatory factor analysis (CFA) which included the following measures: anger in response to integrity-based violations, anger in response to competence-based violations, abusive supervision, and perceived leader effectiveness. Using a parcelling approach (Little, Cunningham, Shahar, \& Widaman, 2002; Matsunaga, 2008; Williams \& O’Boyle, 2008; see also Little, Rhemtulla, Gibson, \& Schoemann, 2013; Marsh, Ludtke, Nagengast, Morin, \& von Davier, 2013 regarding the on-going debate on this issue), the model

TABLE 4

Descriptive Statistics and Zero-Order Correlations of Variables in Study 3

\begin{tabular}{|c|c|c|c|c|c|c|c|c|c|}
\hline Variable & Mean & $S D$ & 1 & 2 & 3 & 4 & 5 & 6 & 7 \\
\hline 1. Leader Gender & .44 & .50 & & & & & & & \\
\hline 2. Leader Age & 36.15 & 9.50 & -0.04 & & & & & & \\
\hline 3. Leader Tenure & 6.53 & 6.31 & 0.07 & $0.50 * * *$ & & & & & \\
\hline $\begin{array}{l}\text { 4. Anger in Response to Competence-based } \\
\text { Violation }\end{array}$ & 3.68 & 1.52 & 0.05 & 0.02 & 0.06 & $(0.92)$ & & & \\
\hline 5. Anger in Response to Integrity-based Violation & 3.98 & 1.64 & 0.03 & 0.07 & -0.06 & $0.51 * * *$ & $(0.93)$ & & \\
\hline 6. Subordinate-reported Abusive Supervision & 2.35 & 1.34 & -0.06 & 0.04 & -0.01 & $0.20 * *$ & 0.13 & $(0.97)$ & \\
\hline 7. Manager-reported Leader Effectiveness & 5.18 & 1.31 & 0.09 & 0.09 & 0.12 & $-0.21^{* *}$ & $0.14^{*}$ & $-0.43^{* * *}$ & (0.89) \\
\hline
\end{tabular}

Note: Reliability coefficients are displayed within parentheses in the diagonal.

${ }^{*} p<.05$

$* * p<.01$

$* * * p<.001$ 
has a good fit with the observed data, $\chi^{2}(38, n=222)=$ 59.704, $p<.05, \chi^{2} / d f=1.57$, comparative fit index $(\mathrm{CFI})=.99, \mathrm{TLI}=.99$, standardized root mean square residual $(\mathrm{SRMR})=.022$, root mean square error of approximation (RMSEA) $=.051$.

To test our hypothesized relationships, we conducted a hierarchical multiple regression analysis to assess the incremental explanatory power of variables in each block (Cohen \& Cohen, 1983). To reduce the impact of the dependency relationship (Tabachnick \& Fidell, 2001) that exists between anger expression in response to the two types of violation, we ran separate regression analyses for anger in response to each type of violation while controlling for the effect of the other. These results are presented in Table 5. Following Aiken and West (1991), we entered the leaders' gender, age, and tenure along with their anger in response to one type of violation as control variables in the first block of the regression equation. In the second step, the independent variable was entered to test for main effects. In the third step, we entered the moderator variable (abusive supervision). Finally, the multiplicative interaction term between anger in response to the type of violation and the moderator variable was entered in the fourth step. Independent and moderator variables were mean-centered (Aiken \& West, 1991).

Supporting Hypotheses $1 \mathrm{a}$ and $1 \mathrm{~b}$, results revealed a negative association between leaderreported anger in response to competence-based violations and manager-reported leader effectiveness
$(B=-.34, p<.001)$ over and above the effects of leader demographic characteristics and leader-reported anger in response to integrity-based violations. Conversely, there was a positive association between leaderreported anger in response to integrity-based violations and manager-reported leader effectiveness $(B=$ $.28, p<.001$ ) over and above the effects of leaders' demographic characteristics and leader-reported anger in response to competence-based violations. Hypotheses $1 \mathrm{a}$ and $1 \mathrm{~b}$ were thus supported.

Hypothesis 3a predicted that abusive supervision moderates the relationship between leader-reported anger in response to integrity-based violations and leader effectiveness, such that the positive relationship between anger expression and perceived leader effectiveness is weaker to the degree that leaders are perceived as abusive. The interaction was statistically significant $(B=-.13, p<.001$; see Figure 2$)$. Simple slope analysis revealed a positive association between anger expressions in response to integritybased violations and perceived leader effectiveness when abusive supervision was low $(B=.45, t=6.56$, $p<.001)$. Conversely, when abusive supervision was high, the relationship between anger expressions in response to integrity-based violations and perceived leader effectiveness was non-significant $(B=.11, t=1.53, p=.13)$. Hypothesis 3 a was therefore supported.

Hypothesis $3 \mathrm{~b}$ proposed that abusive supervision moderates the relationship between anger expressions

TABLE 5

Summary of Hierarchical Regression Results of the Moderating Effect of Abusive Supervision on the Relationship between Anger Expression in Response to Integrity-based versus Competence-based Violation and Leader Effectiveness

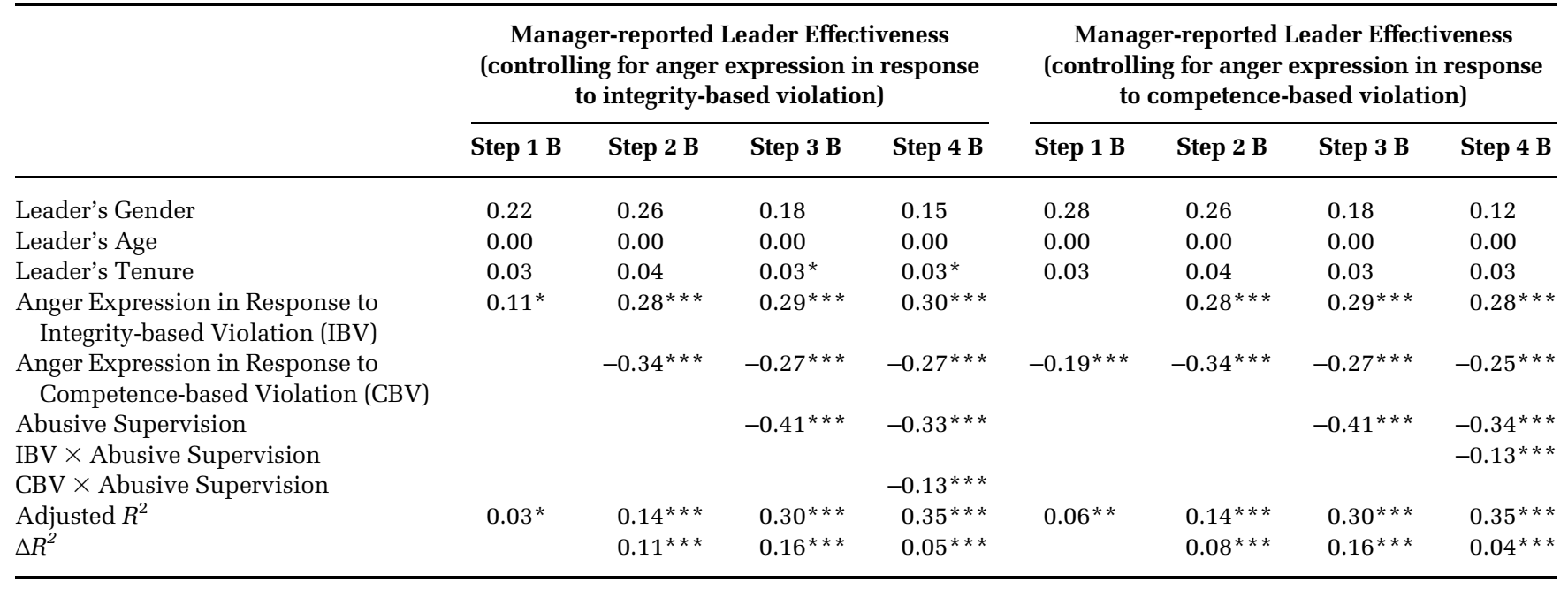

\footnotetext{
${ }^{*} p<.05$

$* * p<.01$

$* * * p<.001$
} 
FIGURE 2

The Interactive Effect of Leader-reported Anger in Response to Integrity-based Violation and Subordinate-reported Abusive Supervision on Manager-reported Leader Effectiveness in Study 3

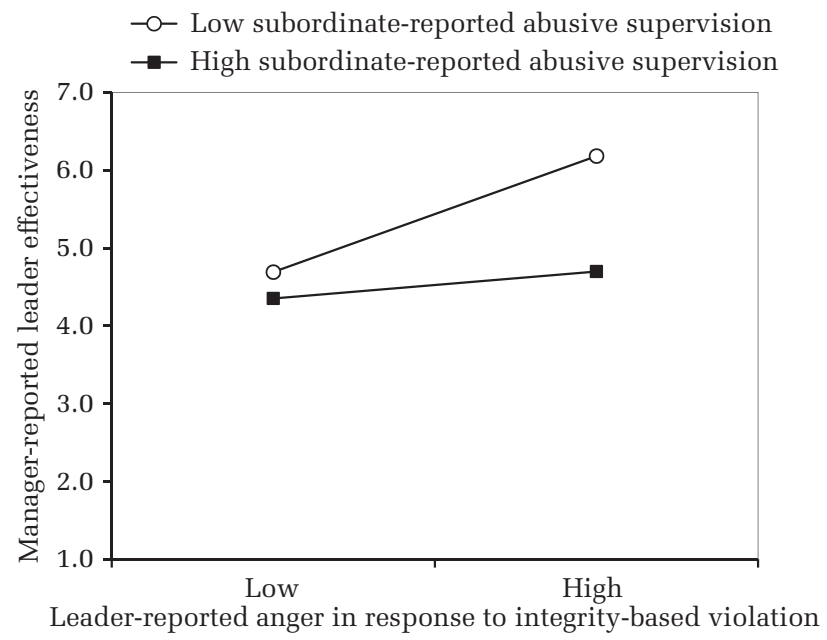

in response to competence-based violations and leader effectiveness, such that the negative relationship between anger expression and leader effectiveness is stronger to the degree that leaders are perceived as abusive. The interaction term was statistically significant ( $B=-.13, p<.001$; see Figure 3 ). Simple slope analysis indicated that the negative association between leader-reported anger expressions

FIGURE 3

The Interactive Effect of Leader-reported Anger in Response to Competence-based Violation and Subordinate-reported Abusive Supervision on Manager-reported Leader Effectiveness in Study 3

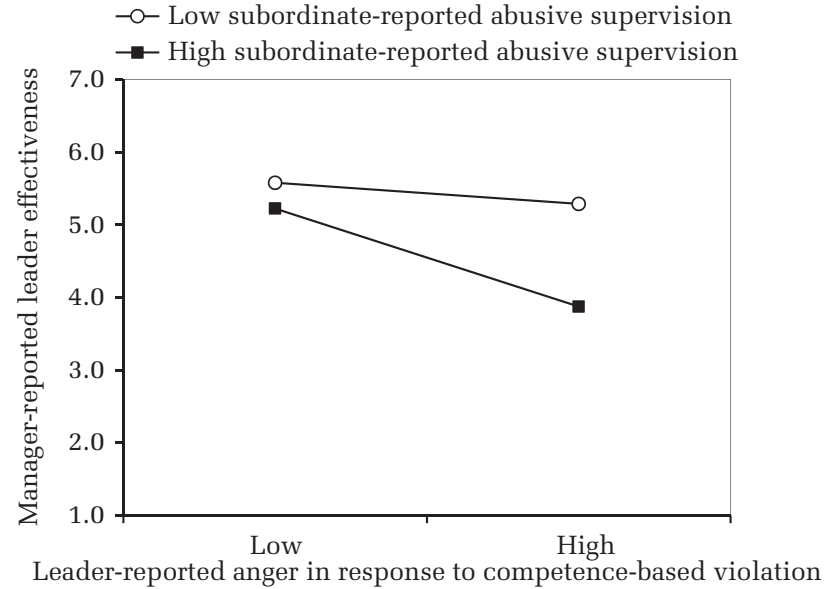

in response to competence-based violations and manager-rated leader effectiveness was significant for leaders who were perceived as being high in abusive supervision $(B=-.44, t=-6.49, p<.001)$. Conversely, the association between leader-reported anger expression in response to competence-based violations and manager-rated leader effectiveness was non-significant for leaders who were perceived as being low in abusive supervision $(B=-.10, t=$ $-1.37, p=.17)$. Hypothesis 3 b was thus supported.

Next, we tested the two interactions in a single regression model so that we could ascertain which (if any) of these two interactions is more predictive of leader effectiveness when both are entered in the model. In terms of main effects, there was a negative association between leader-reported anger in response to competence-based violations and managerreported leader effectiveness $(B=-.36, p<.001)$. Conversely, there was a positive association between leader-reported anger in response to integrity-based violations and manager-reported leader effectiveness $(B=.29, p<.001)$. The interaction between leader-reported anger expressions in response to competence-based violations and abusive supervision significantly predicted perceived leader effectiveness $(B=-.09, p=.04)$. However, the interaction between leader-reported anger in response to integrity-based violations and abusive supervision was not significantly associated with leader effectiveness $(B=-.05, p=.21)$. We should note that the direction of the interaction as well as the simple slopes showed the same (predicted) pattern as in the initial analysis. However, the results of this alternative analysis suggest that the moderating role of abusive supervision in the relationship between anger in response to competence-based violations and perceived leader effectiveness is more robust than the moderating role of abusive supervision in the relationship between anger in response to integritybased violations and leader effectiveness.

\section{GENERAL DISCUSSION}

Although a growing body of research attests to the powerful impact of leaders' anger expressions on followers (for a review, see Van Knippenberg \& Van Kleef, 2016), different views exist on whether anger expression undermines or enhances leader effectiveness. The traditional perspective suggests that anger expressions are destructive (e.g., Glomb \& Hulin, 1997; Lewis, 2000). That is, expressing anger can elicit strong negative reactions from followers and, consequently, effective leaders should strive to refrain from 
anger expression in the workplace. An alternative perspective emphasizes the potentially functional role of anger expression in the leadership process (e.g., Tiedens, 2001; Van Kleef et al., 2009), suggesting that anger expressions can enhance a leader's ability to influence followers and thus enhance leader effectiveness. We propose that these two opposing views on the consequences of leader anger expression can be reconciled by considering: (1) whether the anger expressed by a leader is in response to competence- or integrity-based violations; and (2) whether the leader who expresses anger is perceived as abusive.

Three studies provide general support for these ideas. Study 1 (a laboratory experiment) demonstrated that a leader's anger expressions had opposite effects on participants' evaluations of the leader's effectiveness depending on the type of violation that had elicited the anger. When anger was expressed in response to an integrity-based violation, observers rated the leader as more effective than when the leader expressed no emotion. However, when anger was expressed in response to a competence-based violation, the leader was evaluated as less effective than when the leader expressed no emotion. This study provided the first causal evidence that anger expressions elicited by competence-based violations versus integrity-based violations have differential consequences for leader effectiveness.

Extending these findings using a working sample, Study 2 provided insight into why these divergent effects occurred by considering both the cognitive and affective reactions of followers. We found the type of violation moderated the effects of leaders' anger expressions on perceived leader effectiveness because the type of violation influenced the relative strength of followers' affective and inferential responses to the leader's anger. Leaders' anger in response to integrity-based violations primarily resulted in beneficial inferential responses among followers: followers inferred from the leader's anger that the violation was unacceptable, which led to more positive evaluations of the leader. In contrast, leaders' anger in response to competence-based violations elicited relatively strong negative affective reactions among followers, which undermined their evaluations of the leader's effectiveness.

Study 3 extended these findings by showing that these effects are further influenced by the extent to which a leader is perceived to be abusive. The damaging effects of expressing anger in response to competence-based violations were stronger to the degree that leaders were perceived to be abusive. In contrast, the positive effects of expressing anger in response to integrity-based violations were weaker to the extent that leaders were perceived to be abusive. Therefore, although abusive leaders are known for frequently expressing anger (Keashly, 1998), Study 3 suggests that abusive supervision exacerbates the harm and weakens the benefits of their anger expression.

\section{Theoretical Contributions}

The present findings contribute to research on anger and leadership in several ways. It has been noted that empirical findings pertaining to the effects of leader expressions of anger on perceived leader effectiveness are inconsistent and that these inconsistencies are poorly understood (Van Knippenberg \& Van Kleef, 2016). However, previous research has not considered the possibility that anger expressions in response to different events may produce different outcomes. Indeed, the literatures on the antecedents of leaders' anger expressions and the consequences of anger expressions have developed largely in isolation. By focusing on how different types of violations that cause leaders to express anger influence the consequences of anger expressions, we provide a new and much-needed theoretical integration of these previously disconnected literatures. In addition, a focus on the situation that elicits anger answers the call among organizational scholars to pay more attention to the power of context in understanding important organizational phenomena (Johns, 2006). Although the role of emotions in shaping organizational behavior has been on the research agenda for over two decades and research in the area is blossoming (e.g., Barsade, Brief, \& Spataro, 2003; Côté \& Hideg, 2011; Elfenbein, 2007; Van Kleef et al., 2012; Weiss \& Cropanzano, 1996), most research has focused predominantly on characteristics of the emotion (e.g., its valence) without considering the context in which the emotion is experienced or expressed. We suggest that the type of violation that triggered the anger represents an important feature of the context that can determine whether anger enhances or diminishes leader effectiveness. Effective leadership is not achieved in choosing either to express or to suppress anger, but rather in knowing when to do so.

Although all sorts of events can elicit anger in leaders, we advance the existing scholarship by suggesting that many of these can be meaningfully categorized into two types of violations: those related to competence and those pertaining to integrity. Leaders expect followers to demonstrate technical competence while at the same time adhering to ethical standards (Brown \& Treviño, 2006a). Hence, behaviors that violate leaders' competence 
expectations or integrity expectations can both trigger anger (Fitness, 2000). It is important to clarify that we do not intend this distinction to be viewed as representing two specific behaviors. Rather, the distinction represents two broad categories of behaviors that encompass a number of specific angertriggering events. Illustrating this point, a variety of specific behaviors belonging to each category emerged from our critical incident data. For example, competence-based violations included a dispatcher who lacked the appropriate skills to route calls to cab drivers in a timely fashion and a copy writer who made many mistakes leading to articles having to be rewritten. Integrity-based violations included an employee who posted inappropriate material online that was both false and damaging to the organization's reputation, and a team member who copied information from other people's work in order to meet deadlines.

Incorporating negative events in terms of both competence and integrity violations not only helps us resolve inconsistent findings on the effects of anger but also allows us to connect research on the social effects of emotional expressions (Van Kleef, 2009) with the literature on ethical leadership (Brown \& Treviño, 2006a), thereby contributing to a theoretical integration of these largely isolated areas of inquiry. Despite increased interest in understanding the interpersonal effects of leaders' anger expressions on followers, most research has focused on anger's influence in performance domains (Van Kleef et al., 2012; Van Knippenberg \& Van Kleef, 2016). Our findings regarding the benefits of anger expression in response to integrity-based violations suggest that leaders' anger may play a critical role in shaping followers' ethical behavior as well. Notably, as demonstrated in Study 1, when a follower was reprimanded for ethical misconduct without anger, the leader was perceived as less effective. Anger may not be easily replaced with words or slogans (Frank, 1988), because it signals that a leader's ethical concerns are not just "cheap talk" but actually matter deeply to the leader. The interpersonal effects of anger may thus serve important moral functions in the leadership process.

Our focus on abusive supervision sought to identify a boundary condition of our model. However, our findings also demonstrated the more general importance of leader characteristics in understanding the effects of leaders' expressions of anger. According to attribution theory (Gilbert \& Malone, 1995; Kelley, 1973; Kelley \& Michela, 1980), individuals may attribute others' behaviors to stable dispositional causes (i.e., personality) or to external causes (i.e., characteristics of the situation). Moreover, people are likely to make attributions of others' behaviors in ways that match their expectations (Brewer, 1988; Fiske \& Neuberg, 1990). Integrating this idea with EASI theory, we demonstrate that the effects of anger expressions are influenced by the extent to which the leader is perceived to be abusive. Because followers expect abusive supervisors to mistreat their employees, it is likely that they would see abusive supervisors' anger expressions as originating in their abusive style rather than the situation (e.g., subordinates' lack of competence or integrity). This rationale also resonates with a central tenet of the Dual Threshold Model of Anger (Geddes \& Callister, 2007), which suggests that anger that crosses the "expression threshold" but not the "impropriety threshold" is most likely to produce positive outcomes. Certain types of leaders may cause anger to appear more improper and therefore discourage followers from thinking about the meaning and implications of the anger. Overall, we believe these findings contribute to research on anger and leadership by highlighting the importance of considering leader characteristics and leadership styles in addition to follower characteristics (Van Kleef et al., 2009, 2010) when seeking to understand the effects of anger expression.

\section{Managerial Implications}

The present findings have clear managerial implications. As the quote from Aristotle at the beginning of the article points out, anger is subject to nuance, as are its consequences. Our work provides practitioners with some clarification regarding when anger expression may enhance or undermine leader effectiveness. Effective leadership is achieved neither by abstaining entirely from expressing anger nor by expressing it indiscriminately. Rather, effective leaders are aware of what anger communicates in different contexts and thereby ensure that their expressions of anger elicit positive inferential responses in followers but not negative affective responses. This understanding may therefore equip them with the capacity to maximize the power of anger while minimizing its costs.

This is consistent with a general tenet of theories on emotional intelligence (Mayer \& Salovey, 1997; Mayer, Salovey, \& Caruso, 2008), which emphasize the importance of knowing when to display a particular emotion to maximize positive outcomes. In designing leadership development programs, it would be worthwhile to invest in developing leaders' awareness of situations in which anger expressions are likely to help or hurt. In addition, effective leaders should not only bear in mind the context in 
determining whether anger expressions are warranted, but also understand how their leadership style influences their ability to use anger more effectively. Whereas anger provoked by integrity-based violations can potentially enhance the effectiveness of a leader, the benefits may weaken considerably when the expresser is perceived to be abusive. Therefore, in order to take advantage of anger as an effective tool of influence, leaders must also avoid displaying behavior that could be perceived by others as abusive.

\section{Strengths, Limitations, and Directions for Future Research}

Although different methodologies come with different weaknesses, an important strength of this research is that we conducted multiple studies using both experimental and survey approaches to test the robustness and generalizability of our theoretical model. Data on key constructs were collected using different designs and measures tapping multiple sources. Because we operationalized leader effectiveness as the judgment of a leader in terms of how he or she performs the leadership role (Tsui, 1984), it is plausible that this judgment may differ depending on the perspective of the person who provides the evaluation. Hence, Study 1 measured leader effectiveness by asking observers to evaluate the effectiveness of a hypothetical leader; Study 2 measured employees' perceptions of their leaders' effectiveness; and Study 3 measured leader effectiveness from a higher-level manager's perspective. Although we found that violation type influenced how observers responded to leaders' anger across the three studies, we did not have objective indices of leaders' effectiveness. It thus remains unclear whether expressing anger in response to integrity-based versus competence-based violations also produces opposite effects on followers' actual behaviors. $^{5}$

\footnotetext{
${ }^{5}$ Two additional samples not reported here also found support for the differential relationship between types of violation (i.e., anger expression in response to competence-based violations and anger expression in response to integrity-based violations) and perceived leader effectiveness. In Sample $1(n=164)$, employees reported their supervisors' tendencies to express anger in response to competence-based or integrity-based violations. In Sample 2 ( $n=129)$, supervisors reported their own tendencies to express anger in response to competence-based or integrity-based violations. Both samples show that anger in response to competence-based violations was negatively related to perceived leader effectiveness whereas anger in response to integrity-based violations was positively related to perceived leader effectiveness.
}

Although we conducted three studies, none of these allowed us to test the full model in a single study. In our final study (Study 3), we proposed that abusive supervision acts as a boundary condition to the effects obtained in Studies 1 and 2 because followers are less likely to derive useful information from the anger of leaders perceived to be abusive, regardless of the type of violation that elicited the anger. However, since in Study 3 the incidents involving integrity-based and competence-based violations were provided by the leaders, we could not collect data on followers' inferential or affective responses in the same incidents, which limits our ability to more fully connect and integrate the abusive supervision literature with the findings of Study 2. Furthermore, each leader's abusive supervision was rated by only one subordinate. Given the perceptual nature of abusive supervision (Tepper, 2000), it is possible that this measure only captures a specific employee's perceptions, rather than the leader's overall behavioral style. The findings of Study 3 may thus be limited by how abusive supervision was assessed. Lastly, although Study 3 asked leaders to report on their own anger expressions in two specific situations involving either competenceor integrity-based violation, it is possible that these responses reflect leaders' general tendencies to express anger in similar situations. That is, if a leader reported that $\mathrm{s} /$ he expressed anger in an incident in which a follower violated an ethical principle, that leader may be more likely to express anger in response to integrity-based violations in general. Similarly, a leader may be more likely to express anger in response to competence-based violations across situations if she indicated that she did so in a particular incident. Testing these possibilities was beyond the scope of the current investigation and represents a possible avenue for future research.

As the first investigation of the importance of angereliciting events, the present studies focus on differentiating violations related to competence versus integrity. We did not consider other features of angereliciting events when examining the influence of leader anger expressions. In particular, we did not consider whether the anger-eliciting behavior constitutes a one-time violation or a sustained violation over time. It is conceivable that anger expressed in response to competence-based violations can produce different consequences if the violation is a repeated offense (e.g., an employee consistently shows a lack of skills and knowledge to perform his or her job without showing improvement). Furthermore, although research has shown that people are more likely to have 
strong negative affective reactions when anger is directed at the person rather than at concrete behavior (Steinel, Van Kleef, \& Harinck, 2008), we did not have data on how the anger is expressed. It is possible that anger expressed in an appropriate context could still backfire when directed at the person rather than at the behavior or at a third party. Lastly, our studies examined observers' responses and evaluations of a leader's anger directed at violations committed by someone else. Although we believe the theoretical arguments that the type of violation can shift the balance between inferential and affective responses are not limited to observers, we do not have data on targets of anger expressions to substantiate this possibility.

In light of our finding that abusive supervision weakens the benefits of expressing anger in response to integrity-based violations, the question arises whether positive leadership behaviors strengthen the benefits of expressing such anger. Future research might examine whether anger expressions are more effective when they are expressed by charismatic leaders. It would also be illuminating to examine whether leaders' demographic characteristics influence the effectiveness of their anger expressions. For example, anger expressed by women is more likely to be attributed to dispositional causes than anger expressed by men (Barrett \& Bliss-Moreau, 2009). Future research might examine the role of leaders' gender in shaping how followers respond to anger prompted by different types of violations.

Past research also suggests that intense anger often leads to destructive outcomes, because intense anger tends to be perceived as more inappropriate in organizations than moderate anger (Geddes \& Callister, 2007; Van Kleef et al., 2012). However, given that severe punishment of ethical transgressions often elicits positive responses (Treviño \& Ball, 1992), intense anger expressions in response to ethical transgressions may elicit more positive outcomes than tempered anger expressions. Such a finding would extend the Dual Threshold Model of Anger (Geddes \& Callister, 2007) by further specifying when expressions of anger cross the impropriety threshold depending on the nature of the event that prompted the anger.

\section{CONCLUSION}

The current model and conclusions help reconcile disparate findings pertaining to the effects of leader expressions of anger by offering an integrative perspective that recognizes the differential impact of anger expressions in response to competence- and integrity-based violations. Even though anger is typically considered a negative emotion, anger may not be inherently problematic and at times even helps leaders resolve problems. Expressions of anger may exacerbate an already suboptimal state of affairs when they are displayed in response to competence-based violations, but they may improve the situation when they are shown in response to integrity-based violations. In any case, the benefits of expressing anger can disappear when leaders are perceived to be abusive. Anger, then, is a powerful tool and a source of great managerial influence. A successful leader is likely to be one who wields it with care.

\section{REFERENCES}

Aiken, L. S., \& West, S. G. 1991. Multiple regression: Testing and interpreting interactions. Thousand Oaks, CA: Sage.

Aquino, K., Tripp, T. M., \& Bies, R. J. 2006. Getting even or moving on? Power, procedural justice, and types of offense as predictors of revenge, forgiveness, reconciliation, and avoidance in organizations. The Journal of Applied Psychology, 91: 653-668.

Averill, J. R. 1983. Studies on anger and aggression: Implications for theories of emotion. The American Psychologist, 38: 1145-1160.

Ayman, R. 1993. Leadership perception: The role of gender and culture. In M. M. Chemers \& R. Ayman (Eds.), Leadership theory and research: Perspectives and directions: 137-166. San Diego, CA: Academic Press.

Baron, R. A. 1990. Countering the effects of destructive criticism: The relative efficacy of four interventions. The Journal of Applied Psychology, 75: 235-245.

Barrett, L. F., \& Bliss-Moreau, E. 2009. Affect as a psychological primitive. In M. P. Zanna (Ed.), Advances in experimental social psychology, vol. 41: 167-218. Burlington, MA: Academic Press.

Barsade, S. G. 2002. The ripple effect: Emotional contagion and its influence on group behavior. Administrative Science Quarterly, 47: 644-675.

Barsade, S. G., Brief, A. P., \& Spataro, S. E. 2003. The affective revolution in organizational behavior: The emergence of a paradigm. In J. Greenberg (Ed.), Organizational behavior: The state of the science: 3-52. Mahwah, NJ: Erlbaum.

Bernardo, A. B. I. 2004. McKinley's questionable bequest: Over 100 years of English in Philippine education. World Englishes, 23: 17-31.

Bono, J. E., \& Ilies, R. 2006. Charisma, positive emotions and mood contagion. The Leadership Quarterly, 17: 317-334.

Brethower, D. M. 1993. Strategic improvement of workplace competence I: Breaking out of the incompetence trap. Performance Improvement Quarterly, 6: 17-28. 
Brewer, M. B. 1988. A dual process model of impression formation. In T. K. Srull \& R. S. Wyer (Eds.), Advances in social cognition, vol. 1: 1-36. Hillsdale, NJ: Erlbaum.

Brown, M. E., \& Treviño, L. K. 2006a. Ethical leadership: A review and future directions. The Leadership Quarterly, 17: 595-616.

Brown, M. E., \& Treviño, L. K. 2006b. Socialized charismatic leadership, values congruence, and deviance in work groups. The Journal of Applied Psychology, 91: 954-962.

Brown, M. E., Treviño, L. K., \& Harrison, D. A. 2005. Ethical leadership: A social learning perspective for construct development and testing. Organizational Behavior and Human Decision Processes, 97: 117-134.

Carlsmith, K. M., \& Darley, J. M. 2008. Psychological aspects of retributive justice. Advances in Experimental Social Psychology, 40: 193-236.

Chi, N.-W., \& Ho, T.-R. 2014. Understanding when leader negative emotional expression enhances follower performance: The moderating roles of follower personality traits and perceived leader power. Human Relations, 67: 1051-1072.

Cohen, J., \& Cohen, P. 1983. Applied multiple regression/ correlation analysis for the behavioral sciences (2nd ed.). Hillsdale, NJ: Earlbaum.

Côté, S., \& Hideg, I. 2011. The ability to influence others via emotion displays: A new dimension of emotional intelligence. Organizational Psychology Review, 1: 53-71.

Cowan, D. 2003. Taking charge of organizational conflict: A guide to managing anger and confrontation. Fawnskin, CA: Personhood Press.

Darley, J. M., \& Pittman, T. S. 2003. The psychology of compensatory and retributive justice. Personality and Social Psychology Review, 7: 324-336.

Eberly, M. B., \& Fong, C. T. 2013. Leading via the heart and mind: The roles of leader and follower emotions, attributions and interdependence. The Leadership Quarterly, 24: 696-711.

Edwards, J. 2013. "Why are you wasting my life?": The nasty things Amazon's CEO tells employees when he gets angry. Business Insider, October 10. Retrieved from http://business.financialpost.com/businessinsider/jeff-bezos-the-sarcastic-things-amazons-ceotells-staff-when-he-gets-angry.

Edwards, R. J., \& Lambert, L. S. 2007. Methods for integrating moderation and mediation: A general analytical framework using moderated path analysis. The Journal of Applied Psychology, 12: 1-22.

Ekman, P. 1984. Expression and the nature of emotion. In K. R. Scherer \& P. Ekman (Eds.), Approaches to emotion: 319-344. Hillsdale, NJ: Erlbaum.
Elfenbein, H. A. 2007. Emotion in organizations: A review and theoretical integration. The Academy of Management Annals, 1: 315-386.

Fisher, C. D. 1986. Organizational socialisation: An integrative review. In K. M. Rowland \& G. R. Ferris (Eds.), Research in personnel and human resources management: 101-145. Greenwich, CT: JAI Press.

Fiske, S. T., Cuddy, A. J. C., \& Glick, P. 2007. Universal dimensions of social cognition: Warmth and competence. Trends in Cognitive Sciences, 11: 77-82.

Fiske, S. T., \& Neuberg, S. L. 1990. A continuum of impression formation, from category-based to individuating processes: Influences of information and motivation on attention and interpretation. Advances in Experimental Social Psychology, 23: $1-74$.

Fitness, J. 2000. Anger in the workplace: An emotion script approach to anger episodes between workers and their superiors, co-workers and subordinates. Journal of Organizational Behavior, 21: 147-162.

Forgas, J. P., \& George, J. M. 2001. Affective influences on judgments and behavior in organizations: An information processing perspective. Organizational Behavior and Human Decision Processes, 86: 3-34.

Frank, R. H. 1988. Passions within reason: The strategic role of the emotions. New York, NY: W. W. Norton \& Co.

Frijda, N. H. 1986. The emotions: Studies in emotion and social interaction. Cambridge, U.K.: Maison des Sciences de l'Homme and Cambridge University Press.

Frost, P. J. 2003. The hidden work of leadership. Leader to Leader, 30: 13-18.

Gaddis, B., Connelly, S., \& Mumford, M. D. 2004. Failure feedback as an affective event: Influences of leader affect on subordinate attitudes and performance. The Leadership Quarterly, 15: 663-686.

Gardiner, H. M., Clark-Metcalf, R. C., \& Beebe-Center, J. G. 1980. Feeling and emotion: A history of theories. New York, NY: American Book.

Geddes, D., \& Callister, R. R. 2007. Crossing the line(s): A dual threshold model of anger in organizations. Academy of Management Review, 32: 721-746.

George, J. M. 2000. Emotions and leadership: The role of emotional intelligence. Human Relations, 53: 1027-1055.

Gilbert, D. T., \& Malone, P. S. 1995. The correspondence bias. Psychological Bulletin, 117: 21-38.

Glomb, T. M., \& Hulin, C. L. 1997. Anger and gender effects in observed supervisor-subordinate dyadic interactions. Organizational Behavior and Human Decision Processes, 72: 281-307.

Golden, T. D., Veiga, J. F., \& Simsek, Z. 2006. Telecommuting's differential impact on work-family conflict: 
Is there no place like home? The Journal of Applied Psychology, 91: 1340-1350.

Gooty, J., Connelly, S., Griffith, J., \& Gupta, A. 2010. Leadership, affect and emotions: A state of the science review. The Leadership Quarterly, 21: 979-1004.

Hatfield, E., Cacioppo, J. T., \& Rapson, R. L. 1994. Emotional contagion. Cambridge, U.K.: Cambridge University Press.

Hayes, A. F. 2013. Introduction to mediation, moderation, and conditional process analysis: $A$ regressionbased approach. New York, NY: Guilford Press.

Heldmann, M. L. 1988. When words hurt. New York, NY: New Chapter Press.

Highhouse, S. 2009. Designing experiments that generalize. Organizational Research Methods, 12: 554566.

Hogan, R., \& Emler, N. P. 1981. Retributive justice. In M. J. Lerner \& S. C. Lerner (Eds.), The justice motive in social behavior: 125-143. New York, NY: Plenum Press.

Johns, G. 2006. The essential impact of context on organizational behavior. Academy of Management Review, 31: 386-408.

Keashly, L. 1998. Emotional abuse in the workplace: Conceptual and empirical issues. Journal of Emotional Abuse, 1: 85-117.

Kelley, H. H. 1973. The process of causal attribution. The American Psychologist, 28: 107-128.

Kelley, H. H., \& Michela, J. L. 1980. Attribution theory and research. Annual Review of Psychology, 31: 457-501.

Keltner, D., \& Haidt, J. 1999. Social functions of emotions at four levels of analysis. Cognition and Emotion, 13: 505-521.

Kiewitz, C., Restubog, S. L. D., Shoss, M. K., Garcia, P. R. J. M., \& Tang, R. L. 2016. Suffering in silence: Investigating the role of fear in the relationship between abusive supervision and defensive silence. The Journal of Applied Psychology, 101: 713-742.

Kim, P. H., Ferrin, D. L., Cooper, C. D., \& Dirks, K. T. 2004. Removing the shadow of suspicion: The effects of apology versus denial for repairing competenceversus integrity-based trust violations. The Journal of Applied Psychology, 89: 104-118.

Kim, Y., Min, B., \& Cha, J. 1999. The roles of R\&D team leaders in Korea: A contingent approach. $\boldsymbol{R} \boldsymbol{\varepsilon} \boldsymbol{D}$ Management, 29: 153-166.

Landers, R. N., \& Behrend, T. S. 2015. An inconvenient truth: Arbitrary distinctions between organizational, Mechanical Turk, and other convenience samples. Industrial and Organizational Psychology: Perspectives on Science and Practice, 8: 142-164.
Lazarus, R. S. 1991. Emotion and adaptation. New York, NY: Oxford University Press.

Lerner, J. S., \& Keltner, D. 2000. Beyond valence: Toward a model of emotion-specific influences on judgment and choice. Cognition and Emotion, 14: 473-493.

Lerner, J. S., \& Tiedens, L. Z. 2006. Portrait of the angry decision maker: How appraisal tendencies shape anger's influence on cognition. Journal of Behavioral Decision Making, 19: 115-137.

Lewis, K. M. 2000. When leaders display emotion: How followers respond to negative emotional expression of male and female leaders. Journal of Organizational Behavior, 21: 221-234.

Lindebaum, D., \& Fielden, S. L. 2011. "It's good to be angry": Enacting anger in construction project management to achieve perceived leader effectiveness. Human Relations, 64: 437-458.

Little, T. D., Cunningham, W. A., Shahar, G., \& Widaman, K. F. 2002. To parcel or not to parcel: Exploring the question, weighing the merits. Structural Equation Modeling, 9: 151-173.

Little, T. D., Rhemtulla, M., Gibson, K., \& Schoemann, A. M. 2013. Why the items versus parcels controversy needn't be one. Psychological Methods, 18: 285-300.

Madera, J. M., \& Smith, D. B. 2009. The effects of leader negative emotions on evaluations of leadership in a crisis situation: The role of anger and sadness. The Leadership Quarterly, 20: 103-114.

Marsh, H. W., Ludtke, O., Nagengast, B., Morin, A. J. S., \& von Davier, M. 2013. Why item parcels are (almost) never appropriate: Two wrongs do not make a rightCamouflaging misspecification with item parcels in CRA models. Psychological Methods, 18: 257-284.

Matsunaga, M. 2008. Item parceling in structural equation modeling: A primer. Communication Methods and Measures, 2: 260-293.

Mayer, J. D., \& Salovey, P. 1997. What is emotional intelligence? In P. Salovey \& D. Sluyter (Eds.), Emotional development and emotional intelligence: Educational implications: 3-31. New York, NY: Basic Books.

Mayer, J. D., Salovey, P., \& Caruso, D. R. 2008. Emotional intelligence: New ability or eclectic traits? The American Psychologist, 63: 503-517.

Mitchell, M. S., Vogel, R. M., \& Folger, R. 2015. Third parties' reactions to the abusive supervision of coworkers. The Journal of Applied Psychology, 100: 1040-1055.

Moorman, R. H., Darnold, T. C., \& Priesemuth, M. 2013. Perceived leader integrity: Supporting the construct validity and utility of a multi-dimensional measure in two samples. The Leadership Quarterly, 24: 427-444. 
Morgeson, F. P., Mitchell, T. R., \& Liu, D. 2015. Event system theory: An event-oriented approach to the organizational sciences. Academy of Management Review, 40: 515-537.

Norman, S. M., Avolio, B. J., \& Luthans, F. 2010. The impact of positivity and transparency on trust in leaders and their perceived effectiveness. The Leadership Quarterly, 21: 350-364.

Pancer, S. M., Brown, S. D., \& Barr, C. W. 1999. Forming impressions of political leaders: A cross-national comparison. Political Psychology, 20: 345-368.

Pfeffer, J. 2010. Power: Why some people have it-and others don't. New York, NY: HarperCollins Publishers.

Rajah, R., Song, Z., \& Arvey, R. D. 2011. Emotionality and leadership: Taking stock of the past decade of research. The Leadership Quarterly, 22: 1107-1119.

Rodriguez, R. O., Green, M. T., \& Ree, M. J. 2003. Leading generation X: Do the old rules apply? Journal of Leadership \& Organizational Studies, 9: 67-75.

Schaubroeck, J. M., \& Shao, P. 2012. The role of attribution in how followers respond to the emotional expression of male and female leaders. The Leadership Quarterly, 23: 27-42.

Scherer, K. R., \& Wallbott, H. G. 1994. Evidence for universality and cultural variation of differential emotion response patterning. Journal of Personality and Social Psychology, 66: 310-328.

Scott, W. R., \& Meyer, J. W. 1991. The rise of training programs in firms and agencies: An institutional perspective. In L. L. Cummings \& B. M. Staw (Eds.), Research in organizational behavior, vol. 13: 297326. Greenwich, CT: JAI Press.

Shields, S. A. 2005. The politics of emotion in everyday life: Appropriate emotion and claims on identity. Review of General Psychology, 9: 3-15.

Skarlicki, D. P., Folger, R., \& Tesluk, P. 1999. Personality as a moderator in the relationship between fairness and retaliation. Academy of Management Journal, 42: 100-108.

Steinel, W., Van Kleef, G. A., \& Harinck, F. 2008. Are you talking to me?! Separating the people from the problem when expressing emotions in negotiation. Journal of Experimental Social Psychology, 44: 362-369.

Sweeney, D. 2013. Can CEOs afford to be angry? Huffington Post, September 27. Retrieved from http://www. huffingtonpost.com/deborah-sweeney/can-ceos-affordto-be-angry_b_4002491.html.

Sy, T. 2010. What do you think of followers? Examining the content, structure, and consequences of implicit followership theories. Organizational Behavior and Human Decision Processes, 113: 73-84.

Sy, T., Côté, S., \& Saavedra, R. 2005. The contagious leader: Impact of the leader's mood on the mood of group members, group affective tone, and group processes. The Journal of Applied Psychology, 90: 295-305.

Tabachnick, B. G., \& Fidell, L. S. 2001. Using multivariate statistics. Boston, MA: Allyn and Bacon.

Tepper, B. J. 2000. Consequences of abusive supervision. Academy of Management Journal, 43: 178-190.

Tepper, B. J. 2007. Abusive supervision in work organizations: Review, synthesis, research agenda. Journal of Management, 33: 261-289.

Tiedens, L. Z. 2001. Anger and advancement versus sadness and subjugation: The effect of negative emotion expressions on social status conferral. Journal of Personality and Social Psychology, 80: 86-94.

Treviño, L. K. 1992. The social effects of punishment: A justice perspective. Academy of Management Review, 17: 647-676.

Treviño, L. K., \& Ball, G. A. 1992. The social implications of punishing unethical behavior: Observers' cognitive and affective reactions. Journal of Management, 18: 751-768.

Tsui, A. S. 1984. A role-set analysis of managerial reputation. Organizational Behavior and Human Performance, 34: 64-96.

Van Kleef, G. A. 2009. How emotions regulate social life: The emotions as social information (EASI) model. Current Directions in Psychological Science, 18: 184-188.

Van Kleef, G. A. 2016. The interpersonal dynamics of emotion: Toward an integrative theory of emotions as social information. Cambridge, U.K.: Cambridge University Press.

Van Kleef, G. A., Homan, A. C., Beersma, B., \& Van Knippenberg, D. 2010. On angry leaders and agreeable followers: How leaders' emotions and followers' personalities shape motivation and team performance. Psychological Science, 21: 1827-1834.

Van Kleef, G. A., Homan, A. C., Beersma, B., Van Knippenberg, D., Van Knippenberg, B., \& Damen, F. 2009. Searing sentiment or cold calculation? The effects of leader emotional displays on team performance depend on follower epistemic motivation. Academy of Management Journal, 52: 562-580.

Van Kleef, G. A., Homan, A. C., \& Cheshin, A. 2012. Emotional influence at work: Take it EASI. Organizational Psychology Review, 2: 311-339.

Van Kleef, G. A., Wanders, F., Stamkou, E., \& Homan, A. C. 2015. The social dynamics of breaking the rules: Antecedents and consequences of norm-violating behavior. Current Opinion in Psychology, 6: 25-31.

Van Knippenberg, D., \& Hogg, M. A. 2003. A social identity model of leadership effectiveness in organizations. In B. M. Staw \& R. M. Kramer (Eds.), Research in 
organizational behavior, vol. 25: 243-295. Greenwich, CT: JAI Press.

Van Knippenberg, D., \& Van Kleef, G. A. 2016. Leadership and affect: Moving the hearts and minds of followers. The Academy of Management Annals, 10: 1-45.

Visser, V. A., Van Knippenberg, D., Van Kleef, G. A., \& Wisse, B. 2013. How leader displays of happiness and sadness influence follower performance: Emotional contagion and creative versus analytical performance. The Leadership Quarterly, 24: 172-188.

Vogel, R. M., et al. 2015. A cross-cultural examination of subordinates' perceptions of and reactions to abusive supervision. Journal of Organizational Behavior, 36: 720-745.

Weiss, H. M., \& Cropanzano, R. 1996. Affective event theory: A theoretical discussion of the structure, causes and consequences of affective experiences at work. In B. M. Staw \& L. L. Cummings (Eds.), Research in organizational behavior, vol. 18: 1-74. Greenwich, CT: JAI Press.

Williams, L. J., \& Anderson, S. E. 1991. Job satisfaction and organizational commitment as predictors of organizational citizenship and in-role behaviors. Journal of Management, 17: 601-617.

Williams, L. J., \& O’Boyle, E. H. 2008. Measurement models for linking latent variables and indicators: A review of human resource management research using parcels. Human Resource Management Review, 18: 233-242.

Zacher, H., Rosing, K., Henning, T., \& Frese, M. 2011. Establishing the next generation at work: Leader generativity as a moderator of the relationships between leader age, leader-member exchange, and leadership success. Psychology and Aging, 26: 241-252.
Lu Wang (nick.wang@anu.edu.au) is an associate professor in the Research School of Management at The Australian National University. He received his $\mathrm{PhD}$ in business administration from the University of Illinois Urbana Champaign. His research primarily focuses on emotions in the work context.

Simon Lloyd D. Restubog (simon.restubog@anu.edu.au) is professor of management at the Australian National University. He will be joining the School of Labor and Employment Relations at the University of Illinois at Urbana-Champaign in the Fall of 2018. He received his $\mathrm{PhD}$ in organizational psychology from the University of Queensland. His research focuses on the dark side of human behavior in organizations, employment relationships, and career development.

Bo (Jeff) Shao (jeff.shao@rmit.edu.au) is a lecturer in the School of Management at the RMIT University in Melbourne, Australia. He received his $\mathrm{PhD}$ in management from the UNSW Sydney, Australia. His research examines leadership effectiveness from emotion and cultural perspectives.

Vinh N. Lu (vinh.lu@anu.edu.au) is an associate professor in Marketing in the Research School of Management at The Australian National University. He received his $\mathrm{PhD}$ from the University of Adelaide. His research focuses on service delivery, career development, and relationship marketing.

Gerben A. van Kleef (g.a.vankleef@uva.nl) is professor and chair of the Social Psychology Department of the University of Amsterdam, the Netherlands. He received his $\mathrm{PhD}$ in work and organizational psychology (2004) from the University of Amsterdam and has held visiting professorships at UC Berkeley and Columbia Business School. His primary research interests revolve around emotion, power, morality, conflict, and social influence. 